\title{
LAS ESTADÍSTICAS DE GÉNERO EN LA PARTICIPACIÓN POLÍTICA* Santander (Colombia)
}

\author{
Gracialiana Moreno Echavarría \\ Especialista en Gerencia Social y Administración Pública, Universidad Industrial de Santander (UIS) - \\ Escuela Superior de Administración Pública (ESAP) Bucaramanga (Colombia); Trabajadora Social, (UIS) \\ Bucaramanga, (Colombia). E: mail: graciliana@yahoo.com;
}

\section{Esmeralda Prada Mantilla}

Magíster en Economía y Ciencias Sociales, Universidad Nacional de Colombia (Colombia), Economista, Universidad Nacional de Colombia (Colombia). Docente - Investigadora, Universidad Santo Tomás Seccional Bucaramanga (Colombia). E-mail: lucumalima@gmail.com

\section{Doris Lamus Canavate}

Doctora en Estudios Culturales, Universidad Andina Simón Bolívar (Ecuador); Magíster en Ciencias Políticas, Facultad Latinoamericana de Ciencias Sociales FLACSO (Ecuador). Socióloga, Universidad Autónoma del Caribe, Barranquilla (Colombia). Docente Investigadora Instituto de Estudios Políticos Universidad Autónoma de Bucaramanga (Colombia). E-mail: dlamus@unab.edu.co

\begin{abstract}
Resumen
El presente texto pretende revisar las estadísticas sobre participación femenina, en el marco de la construcción de una sociedad y un proyecto de ciudad, además de la igualdad de oportunidades y equidad entre géneros, al incorporar voz, propuestas y acciones de las mujeres en su heterogeneidad, para que sean recibidas y valoradas adecuadamente, sobre todo cuando las mujeres son más de la mitad de la población. La Constitución Política de 1991, ha sido un paradigma central en el avance de los derechos y participación de las mujeres, a partir del cual aumenta gradualmente su presencia en espacios de elección popular y de decisión. En el departamento de Santander (Nororiente colombiano) continúa siendo muy baja. Ninguna de las 15 mujeres que se candidatizaron a la Cámara de Representantes en las elecciones de 2006 fue elegida, ni alcanzaron curul las aspirantes al Senado.
\end{abstract}

\section{Palabras clave}

Participación política, participación femenina, género.

\begin{abstract}
The present text seeks to revise the statistics on feminine participation, in the mark of the construction of a society and a city project, besides the equality of opportunities and justness among goods, when incorporating voice, proposals and the women's actions in its heterogeneity, so that they are received and valued appropriately, mainly when the women are more than half of the population. The Political Constitution of 1991 has been a central paradigm in the advance of the rights and the women's participation, starting from which increases its presence gradually in spaces of popular election and of decision. In the department of Santander (Colombian northeast) it continues being very low. None of the 15 women that you candidatizaron to the Camera of Representatives in the elections of 2006 was chosen, neither they reached curul the applicants to the Senate.
\end{abstract}

\section{Key Words}

Political participation, feminine participation, gender. 


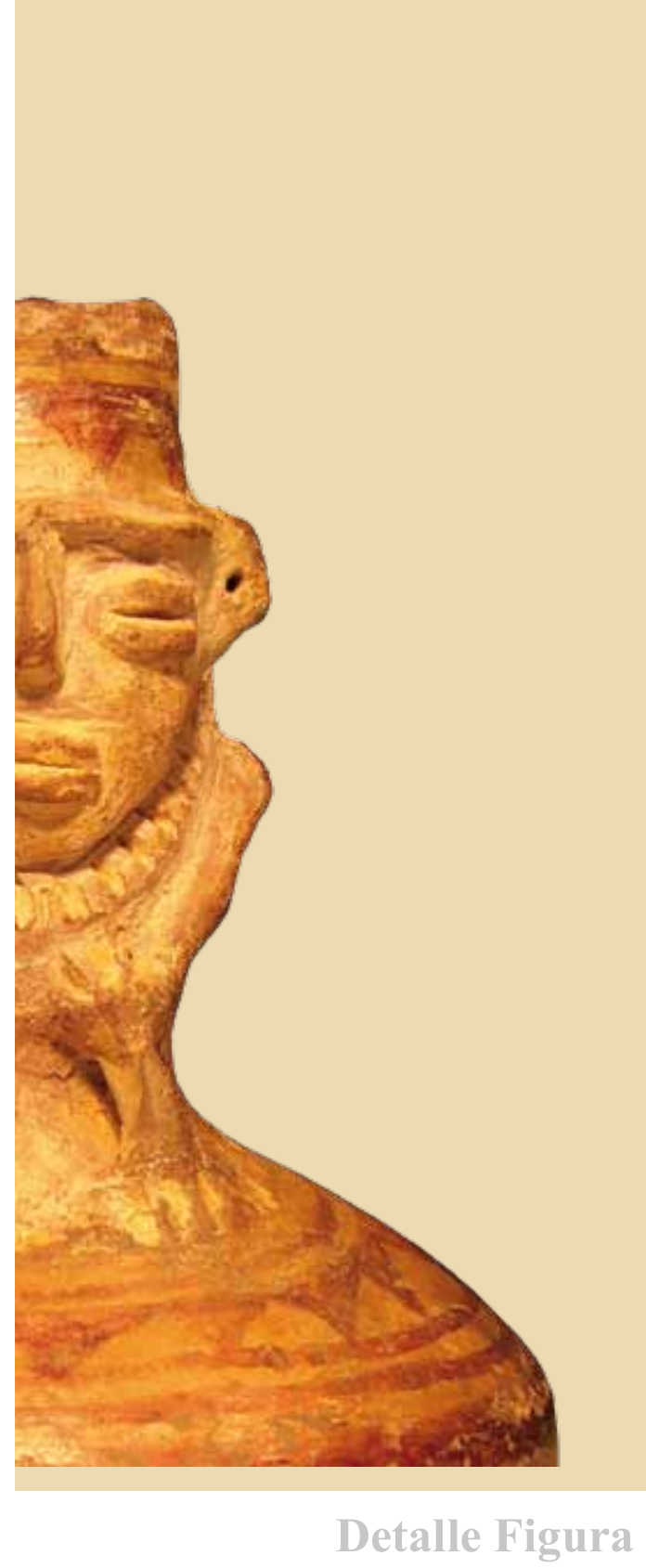

Múcura antropomorfa 


\title{
LAS ESTADÍSTICAS DE GÉNERO EN LA PARTICIPACIÓN POLÍTICA* Santander (Colombia)
}

\author{
Gracialiana Moreno \\ Esmeralda Prada Mantilla \\ Doris Lamus Canavate
}

La carencia de datos cuantitativos y cualitativos ha contribuido a que las situaciones discriminatorias contra los grupos en situación de desventaja todavía se presenten y, en algunos casos, se intensifiquen. La elaboración de indicadores, la recolección de datos estadísticos, la creación de sistemas de información y la producción de análisis de la participación social y política con perspectiva de género, son una necesidad global y un mandato para los Estados que han ratificado los instrumentos que protegen y garantizan de manera especial los derechos fundamentales.

En especial en la Declaración y Plataforma de Acción de Beijing suscritos por Colombia en la Cuarta Conferencia Mundial sobre la Mujer de 1995', se adquirió el compromiso de elaborar indicadores cuantitativos y cualitativos para facilitar la evaluación del rendimiento económico y fortalecer la participación política de las mujeres en los puestos de mayor decisión.

En el ámbito interno, la Ley 823 de 2003 establece en su artículo $4^{\circ}$ que para la formulación de las políticas de igualdad de oportunidades para las mujeres y el fortalecimiento de las instituciones responsables de su ejecución, el Gobierno Nacional deberá, entre otras acciones, promover la adopción de indicadores de

\footnotetext{
El presente artículo de investigación forma parte del trabajo realizado por la Fundación Mujer y Futuro para la Alcaldía de Bucaramanga, titulado Brechas de Género: Diagnóstico para la formulación de un plan de igualdad para las mujeres en Bucaramanga (2008). Secretaría de Desarrollo Social. Contrato de Apoyo No. 018 de 2007. Investigadoras: Graciliana Moreno Echavarría; Esmeralda Prada Mantilla; Doris Lamus Canavate.

1 Conferencia celebrada en Beijing (China), del 4 al 15 de septiembre de 1995.
} 
género en la producción de estadísticas de los organismos e instituciones públicas y privadas. Por ello, el surgimiento del primer Observatorio de Asuntos de Género -OAG- en Colombia, liderado por la Consejería Presidencial para la Equidad de la Mujer, es un hecho importante que es necesario resaltar, hacia el fortalecimiento de la equidad social y de la equidad de género en el país.

\section{COMPORTAMIENTO DE LA PARTICIPACIÓN POR GÉNERO EN ESCENARIOS DE ELECCIÓN POPULAR A NIVEL NACIONAL}

Antes de 1954 en Colombia las mujeres no eran consideradas ciudadanas y no tenían derecho a elegir y ser elegidas, por lo tanto, no tenían derecho a la participación política. Si bien el logro del derecho al sufragio para las mujeres en 1954 significó un posicionamiento político ${ }^{2}$, con él, no se logró alcanzar la ciudadanía plena. Uno de los primeros efectos del derecho adquirido por las mujeres hace 50 años, en ese entonces, fue el nombramiento de Esmeralda Arboleda de Uribe como la primera Ministra que tuvo el país, y la primera participación activa por parte de las ciudadanas colombianas en los comicios de 1957.

Al observar el comportamiento en cifras de la participación en cargos de decisión como el Congreso de la República, es evidente la brecha de desigualdad existente a nivel de género en este ámbito de participación, constituyéndose en un déficit democrático, cuya escasa representación e inclusión de las mujeres en los cargos de decisión genera una insuficiente influencia transformativa en la vida social y política del país.

Figura 1. Participación por género en el Congreso

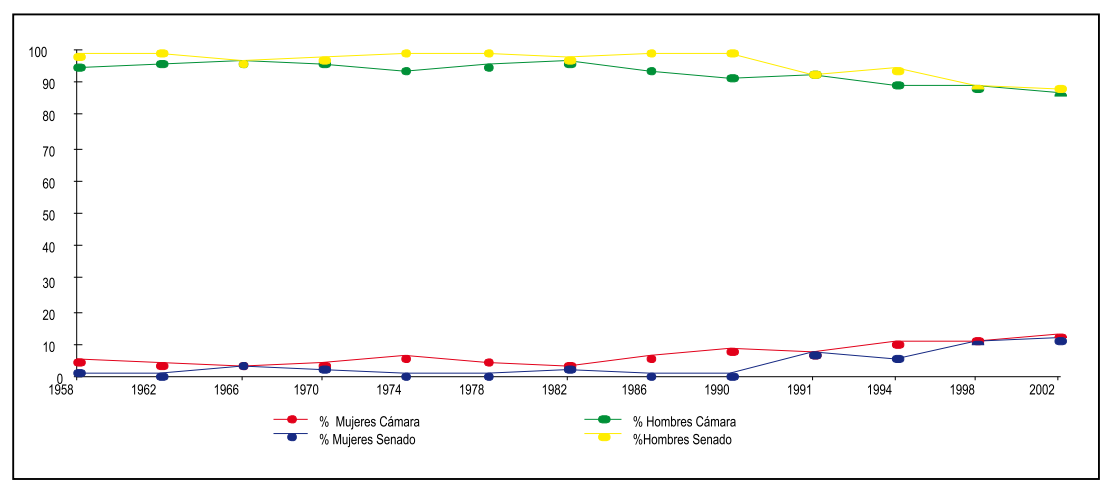

Fuente: Observatorio Mujer y Participación Política - (Wills, 2005) 
En las entidades territoriales intermedias y locales la situación no ha sido muy distinta, si partimos de considerar el comportamiento desde que se llevó a cabo la primera elección de gobiernos departamentales y locales ${ }^{3}$. En el caso de las Gobernaciones las mujeres no han alcanzado más allá del 6,25\%, frente a los hombres que representan más del $93 \%$ del total de los 32 departamentos existentes en el país.

Tabla 1. Comportamiento de la participación por género en Gobernaciones

\begin{tabular}{|c|c|c|c|c|}
\hline Período & Departamento & Partido Político & No. Gobernadoras & $\%$ \\
\hline $1992-1994$ & Caldas & Partido Conservador & 1 de 32 & 3,20 \\
\hline 1995 - 1997 & $\begin{array}{c}\text { Cundinamarca } \\
\text { y Quindío }\end{array}$ & Partido Liberal & 2 de 32 & 6,25 \\
\hline $1998-2000$ & Ninguna mujer fue elegida & & 0 de 32 & 0 \\
\hline $2001-2003$ & $\begin{array}{l}\text { Risaralda y } \\
\text { San Andrés }\end{array}$ & Partido Conservador & 2 de 32 & 6,25 \\
\hline $2004-2007$ & $\begin{array}{l}\text { Quindío y } \\
\text { Amazonas }\end{array}$ & $\begin{array}{l}\text { Partido Liberal - } \\
\text { Movimiento Nal } \\
\text { Progresista }\end{array}$ & 2 de 32 & 6,25 \\
\hline
\end{tabular}

Fuente: Fundación Mujer y Futuro ${ }^{4}$

Después de más de 15 años de establecida la elección popular de gobernadores/as, tan sólo 6 Departamentos del total han elegido a una mujer.

Figura 2. Participación por género en Asambleas Departamentales

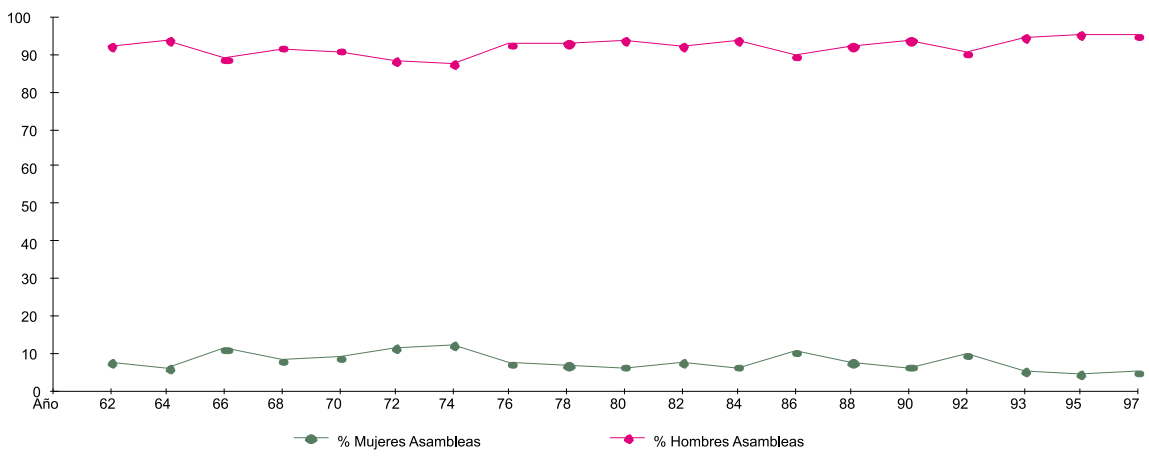

Fuente: Observatorio Mujer y Participación Política.

3 La primera elección popular de gobernadores y gobernadoras se llevó a cabo el 27 de octubre de 1991 y la elección de alcaldes y alcaldesas se dio, por primera vez, el 13 de marzo de 1988 .

4 Elaborado a partir de información de FESCOL- Programa de Apoyo a la descentralización GTZEstadísticas electorales - Dirección de Gestión electoral. Registraduría Nacional del Estado Civil. www.federacionnacionaldedepartamentos.org.co 
Desde la primera elección popular de diputados/as en el año 1958, que permitió la llegada de 31 mujeres a esta corporación, la participación en este espacio aumentó lentamente sin superar el 4\%. No obstante a partir de la Constitución del 91 la participación de las mujeres diputadas en las Asambleas Departamentales ha ido en aumento hasta alcanzar en el período 2004-2007 un número de 64 elegidas (que equivale al 16,12\%) de un total de 397 diputados en el país (Arango, Guacaneme, 2005).

Figura 3. Participación por género en Alcaldías

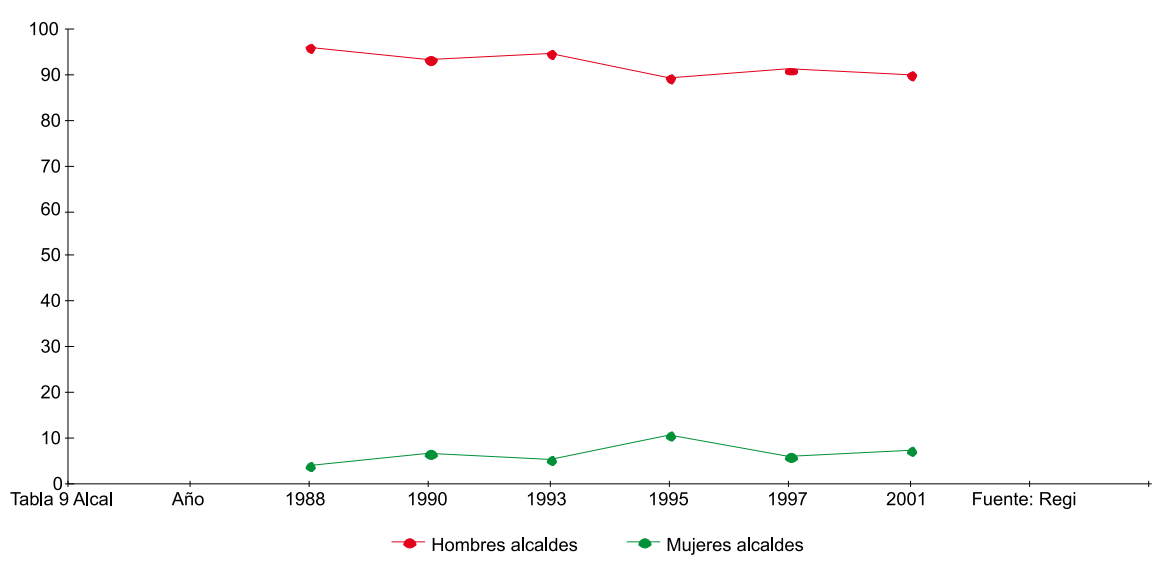

Fuente: Observatorio Mujer y Participación Política.

\section{Panorama nacional sobre la participación política por género en las diferentes ramas del poder público durante los dos últimos períodos electorales (1999 - 2007).}

Aunque la Constitución Política de 1991, ha sido un paradigma central para el avance de las mujeres, a partir del cual aumenta de manera gradual su presencia en los espacios de elección popular y de decisión, ésta es muy baja, como lo demuestran las siguientes cifras comparativas para las tres Ramas del Poder Público. 
Figura 4. Participación por género en Ministerios

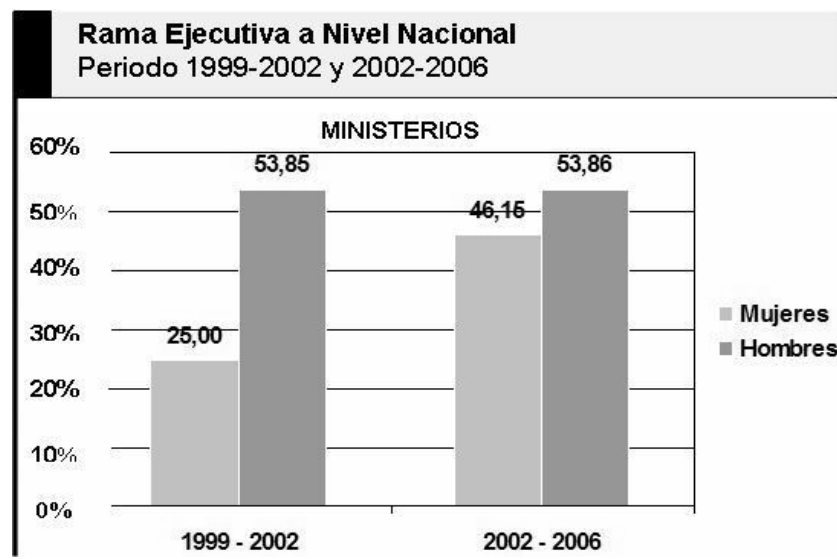

Fuente: Consejería Presidencial para la Equidad de la Mujer. Boletín Observatorio de Asuntos de Género. Mayo- agosto de 2004.

Se observa un importante incremento en la aplicación de la Ley de Cuotas ${ }^{5}$ a nivel de ministerios en el presente período administrativo. Durante el período analizado la participación en Ministerios alcanzó el 46.15\% y Consulados el 27,54\%, dentro de los que han sido encabezados por mujeres están: Relaciones Exteriores, Educación, Comunicaciones, Medio Ambiente y Cultura. En las Embajadas participan menos mujeres que en los Consulados, es decir, hay más mujeres que ocupan cargos de menor decisión y hay menos mujeres en los de mayor decisión. Este comportamiento se mantiene en las distintas ramas, con excepción del caso de los ministerios.

En Colombia la participación efectiva de las mujeres en las distintas regiones atraviesa por una serie de limitaciones enmarcadas en relaciones de poder desiguales entre mujeres y hombres. Esto evidencia una separación en el ordenamiento social, entre lo público y lo privado, que se ve reflejada en problemas de carácter estructural. Por ejemplo, la escasa participación política de las mujeres y las altas tasas de violencia intrafamiliar, impiden el ejercicio libre y autónomo de los derechos de las mujeres, reproducen esquemas de subordinación y perpetúan su discriminación en la sociedad.

5 Ley 581 de 2000 establece la obligatoriedad de la participación de un mínimo del $30 \%$ de mujeres en los cargos de máximo nivel decisorio y otros niveles de decisión en las tres ramas y órganos del poder público. 
Figura 5. Participación por género Gobernaciones y Alcaldías

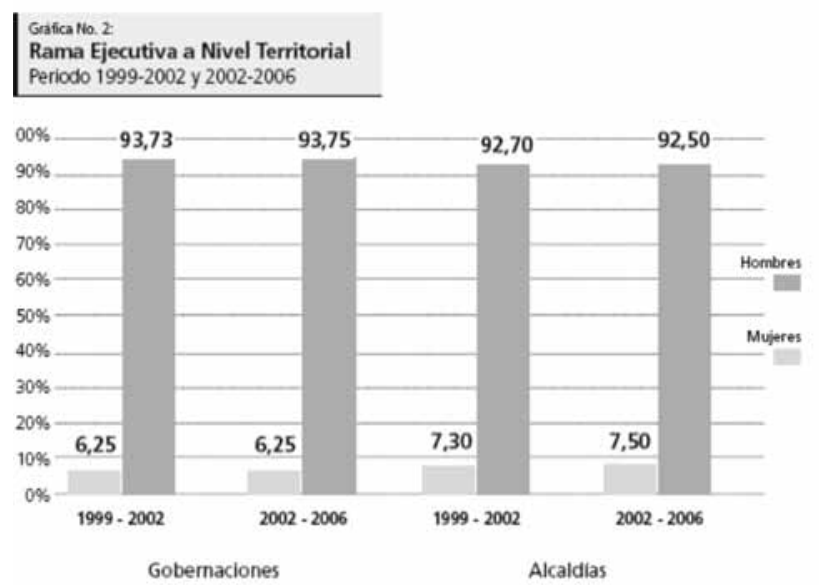

Fuente: Consejería Presidencial para la Equidad de la Mujer. Observatorio de Asuntos de Género. Mayo- agosto de 2004.

Las cifras revelan un leve aumento en el número de alcaldesas entre los dos períodos, mientras la participación de mujeres en las gobernaciones se mantiene en el mismo nivel para los dos períodos analizados. Tanto en gobernaciones como en alcaldías su participación es muy baja en relación con la de los hombres que ocupan aproximadamente el $90 \%$ de estos cargos.

Figura 6. Participación por género Congreso
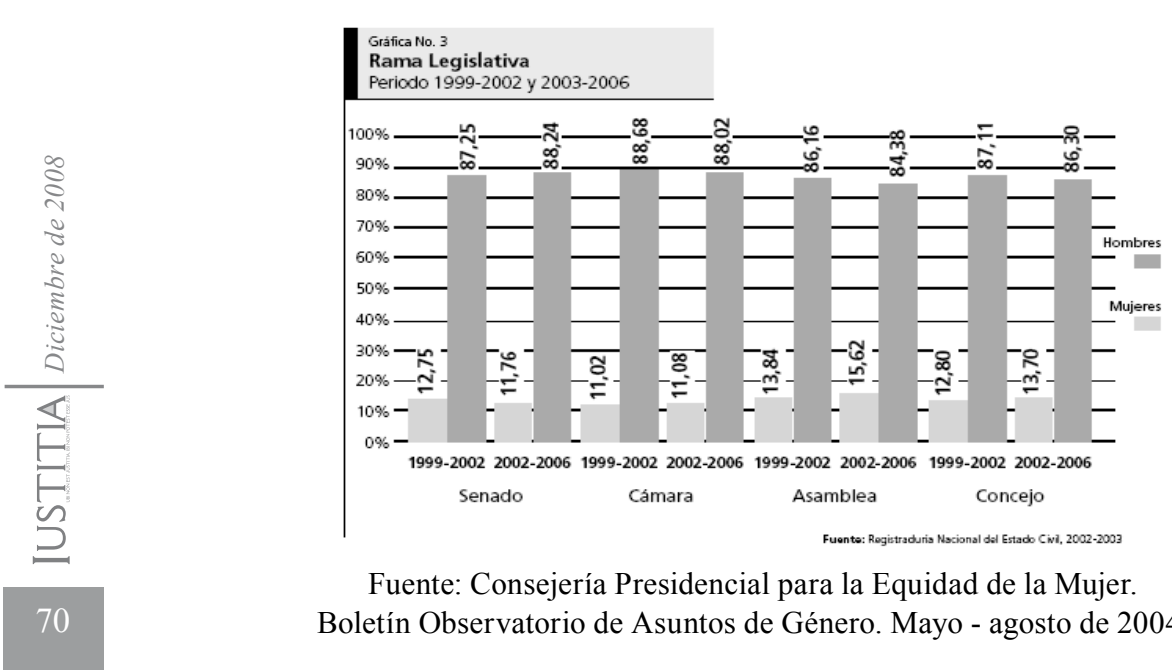

Fuente: Consejería Presidencial para la Equidad de la Mujer. Boletín Observatorio de Asuntos de Género. Mayo - agosto de 2004. 
En la rama legislativa la participación de las mujeres es un poco más alta que en la rama ejecutiva, a nivel territorial. Como se observa, en el período legislativo 20022006 las Representantes aumentaron, y superaron levemente a las elegidas para el Senado, quienes en esta oportunidad disminuyeron en su elección. Sin embargo, la elección de mujeres es muy baja en relación con la elección de hombres, que ocupa en promedio un $88 \%$ de las curules en el Congreso.

Es en la Rama Judicial donde observamos la menor participación total de mujeres (16.67\% promedio). Sin embargo, al desagregar en cada Corte, se refleja un comportamiento semejante al de las otras ramas, pues demuestra que la más baja participación se encuentra en la Corte Suprema de Justicia y la Corte Constitucional; levemente mejora en el Consejo Superior de la Judicatura y una mayor participación la logran en el Consejo de Estado.

Figura 7. Participación por género en Rama Judicial

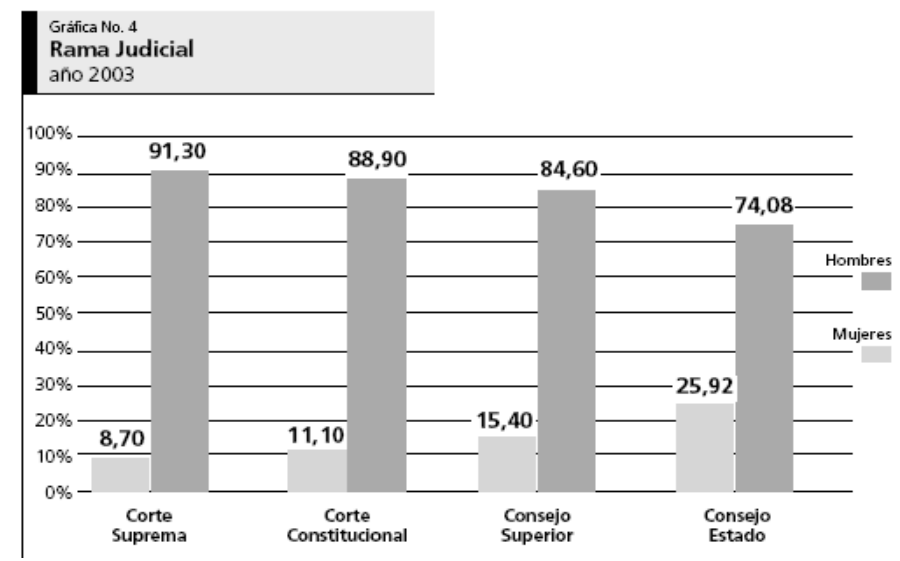

Fuente: Consejería Presidencial para la Equidad de la Mujer. Boletín. Observatorio de Asuntos de Género. Mayo - agosto de 2004.

En conclusión, en materia de cargos en las tres ramas del poder público, estas cifras revelan un sesgo discriminatorio. Demuestran que en el ejercicio de los derechos políticos, a pesar de la alta participación de las mujeres como potencial electoral, en las jornadas comunitarias, en la administración pública y en partidos y movimientos políticos, su postulación y elección es muy baja. Por lo tanto, se requiere avanzar en el ejercicio de políticas públicas existentes que promueven las posibilidades de participación en los espacios de decisión, para hacer visibles y reconocer como actoras políticas a las mujeres. 


\section{COMPORTAMIENTO DE LA PARTICIPACIÓN POLÍTICA POR GÉNERO EN SANTANDER (Arango, Guacaneme, 2005)}

En el Departamento de Santander ninguna de las 15 mujeres que se candidatizaron a la cámara de representantes en las elecciones de 2006 salió elegida, como tampoco alcanzaron la curul las mujeres aspirantes al Senado. Como se indica en el cuadro los porcentajes de participación más altas de participación femenina ha sido en la Asamblea Departamental en el período 2001 - 2003 con un 15,8\% del total de diputados elegidos. No obstante, esta participación se reduce para el siguiente período y se mantiene con 2 curules en el período iniciado de acuerdo con los resultados electorales de octubre de 2007 (ver Cuadros siguientes). Para el período 2004 - 2007 se postularon 22 mujeres de 102 aspirantes a la Asamblea.

Tabla 2. Participación política por género en Santander

\begin{tabular}{|c|c|c|c|c|c|c|c|c|c|c|c|c|}
\hline \multirow[b]{2}{*}{$\begin{array}{l}\text { NSTANCIAS/PERIODO } \\
\text { DE GOBIERNO } \\
\text { DEPARTAMENTO } \\
\text { DE SANTANDER }\end{array}$} & \multicolumn{4}{|c|}{$1998-2000$} & \multicolumn{4}{|c|}{$2001-2003$} & \multicolumn{4}{|c|}{$2004-2007$} \\
\hline & 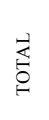 & 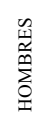 & 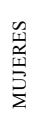 & $\begin{array}{c}\% \\
\text { PARTICIPACIÓN } \\
\text { FEMENINA }\end{array}$ & $\underset{\leftarrow}{\rightleftarrows}$ & 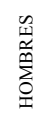 & 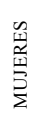 & $\begin{array}{c}\% \\
\text { PARTICIPACIÓN } \\
\text { FEMENINA }\end{array}$ &  & 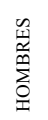 & 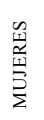 & $\begin{array}{c}\% \\
\text { PARTICIPACIÓN } \\
\text { FEMENINA }\end{array}$ \\
\hline Asamblea Dptal & 19 & 17 & 2 & $10,5 \%$ & 19 & 16 & 3 & $15,8 \%$ & 19 & 17 & 2 & $10,5 \%$ \\
\hline Alcaldías & 87 & 84 & 3 & $3,4 \%$ & 87 & 81 & 6 & $6,9 \%$ & 87 & 81 & 6 & 6,9 \\
\hline Concejos & 758 & 691 & 67 & $8,8 \%$ & 841 & 765 & 76 & $9,0 \%$ & 817 & 737 & 80 & $9,1 \%$ \\
\hline
\end{tabular}

Fuente: Registraduría del Estado Civil. Cuadro elaborado por FMF.

De los 87 municipios de Santander el porcentaje de participación femenina en alcaldías y concejos se ha incrementado y alcanzó para el periodo 2004-2007 un total de 80 curules que equivalen al $9,1 \%$ del total. De la misma manera para las elecciones del período 2004-2007 se postularon sólo 544 mujeres de un total de 3.747 inscritos, lo que representa el 14,5\%. Aunque es evidente la baja participación e inclusión de las mujeres frente a la de los hombres, aún así, hay que señalar como hecho positivo la tendencia general de crecimiento en el porcentaje de participación en estas instancias de decisión.

Resultados de los comicios electorales de octubre de 2007

En el Departamento de Santander y de acuerdo con los resultados electorales suministrados por la Registraduría Nacional del Estado Civil el número de personas 
inscritas por sexo como aspirantes a la diputación en la Asamblea departamental fue de 93 hombres frente a 14 mujeres.

Figura 8. Inscritos por partido y sexo a la Asamblea de Santander.

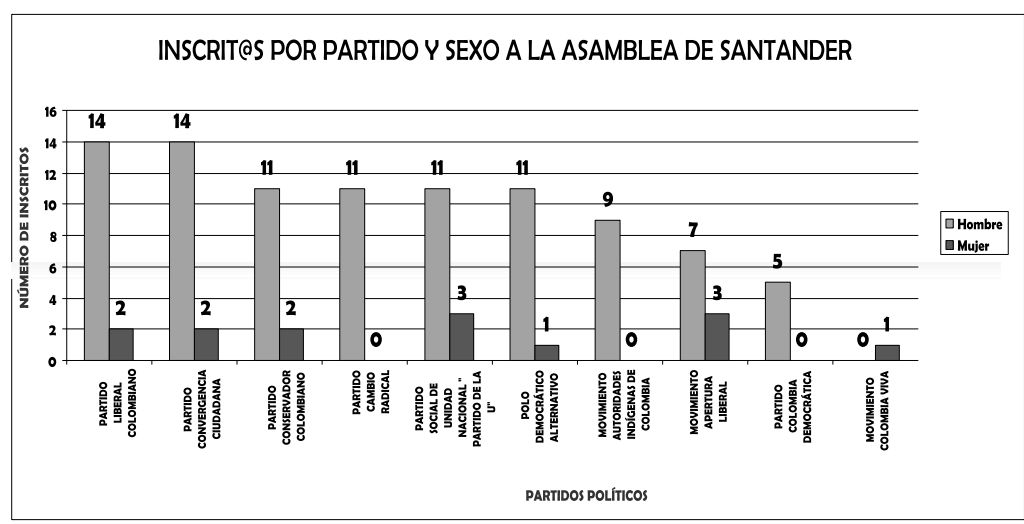

Fuente: Registraduría Nacional del Estado Civil - Santander.

De este total de inscritos resultaron elegidas 2 mujeres y 14 hombres, se aseguró una participación femenina equivalente al 13\%, y se mantuvo de esta forma la misma proporción de participación del período pasado.

Figura 9. Número de diputados elegidos por sexo y partido.

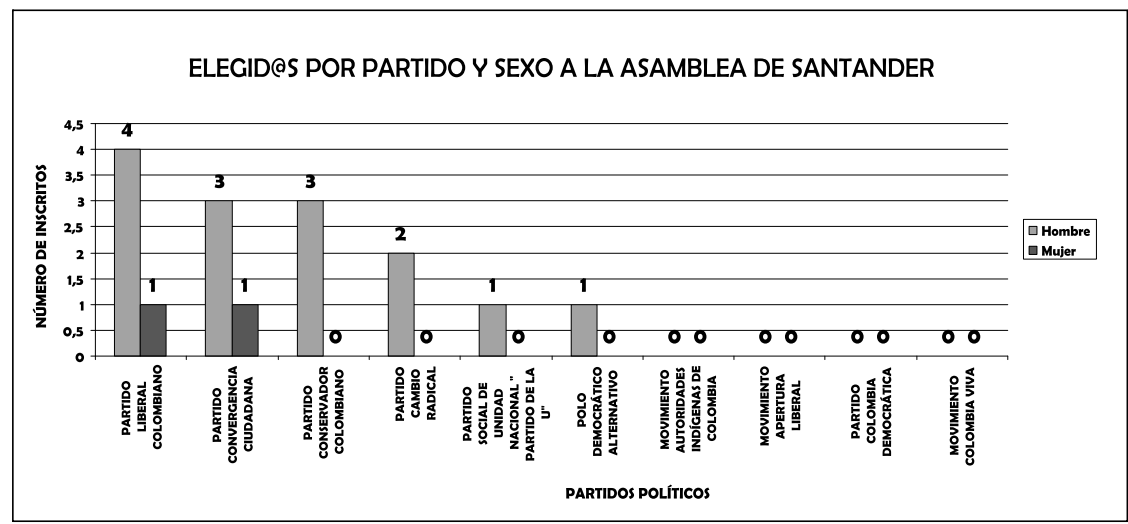

Fuente: Fundación Mujer y Futuro con información de Registraduría Nacional del Estado Civil - Santander. 


\section{Las cifras para Bucaramanga en el 2007}

De acuerdo con la información suministrada por la Registraduría del Estado Civil en Bucaramanga existe un potencial electoral de 412.232 personas aptas para votar, distribuidos así: 54\% mujeres y 46\% hombres. Así mismo el total de votantes fue de 132.754 mujeres (56\%) y 105.687 hombres (44\%), es decir, en ambos casos no sólo en el potencial, sino además en el porcentaje de votantes la participación femenina es mayoritaria.

Figura 10. Relación porcentual de potencial y votantes por sexo



Fuente: Registraduría Nacional del Estado Civil - Santander. Gráfico elaborado por FMF.

En total se inscribieron como aspirantes al concejo de Bucaramanga un total de 288 candidatos/as distribuidos así: 254 hombres (88\%) y 34 mujeres (12\%), sin embargo resultaron elegidos 14 hombres (74\%) y 5 mujeres $(26 \%)$, lo cual significa no sólo un incremento importante en la cuota de participación femenina al pasar de 3 a 5 concejalas elegidas para el período 2008-2011, sino además un porcentaje de éxito de las mujeres equivalente al 15\%. 
Figura 11. Inscritos por partido y sexo al Concejo de Bucaramanga.

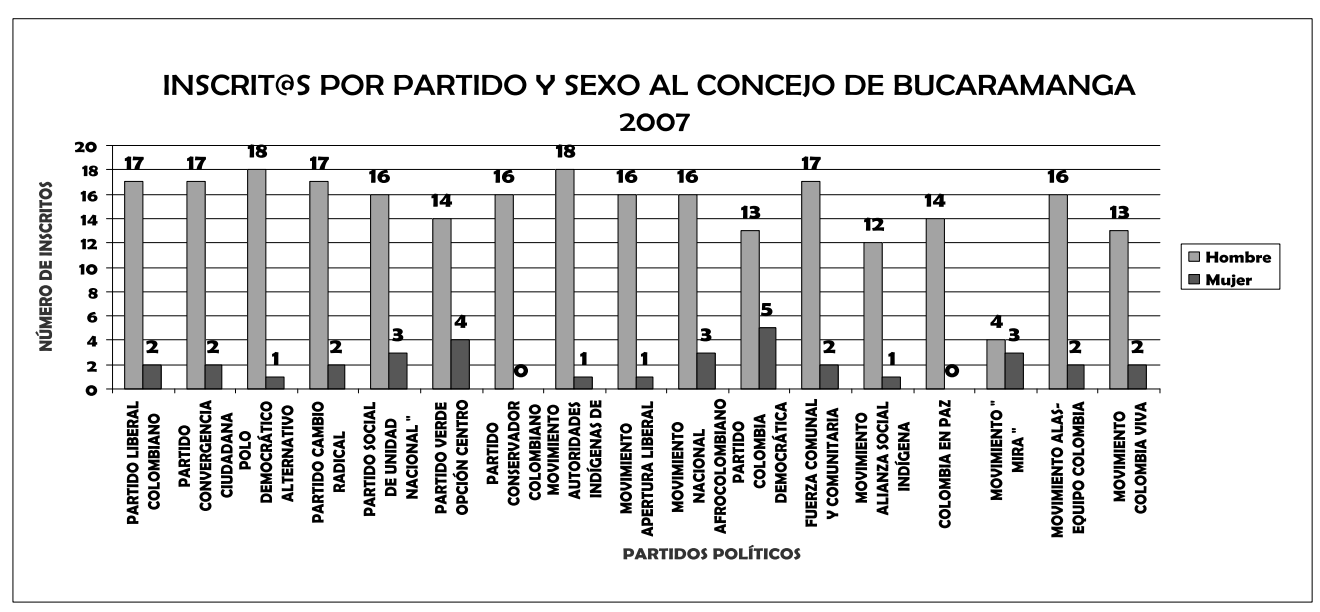

Fuente: Registraduría Nacional del Estado Civil - Santander. Gráfico elaborado por FMF.

Figura 12. Número de elegidos por sexo y partido al Concejo de Bucaramanga.

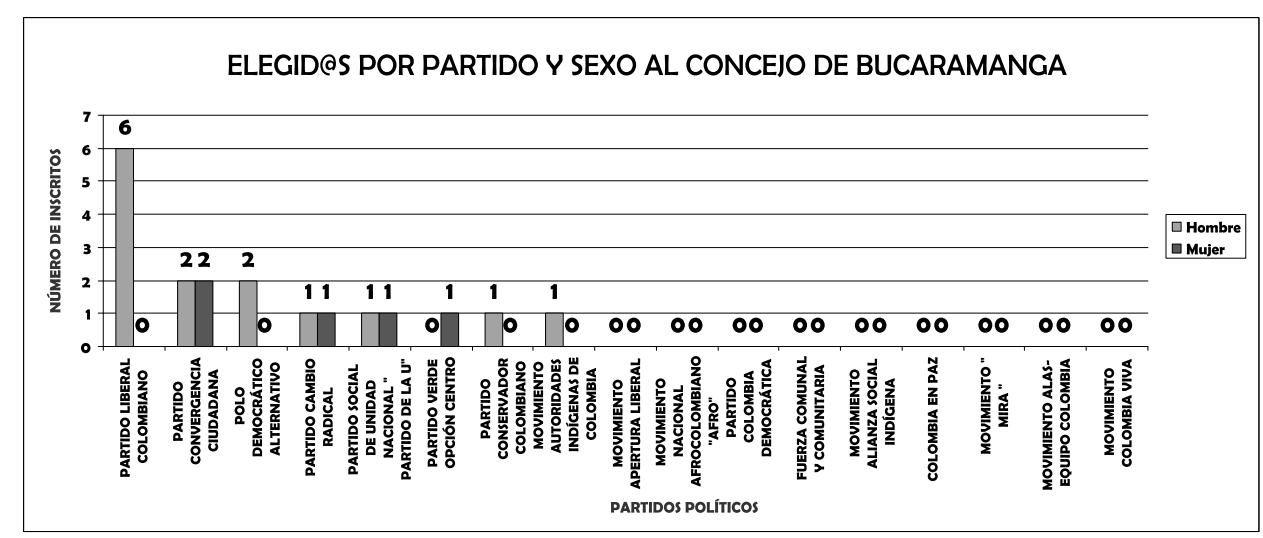

Fuente: Registraduría Nacional del Estado Civil - Santander. Gráfico elaborado por FMF. 
De acuerdo con las cifras uno de los órganos de mayor participación femenina a nivel político en Bucaramanga se da en las comunas. Las Juntas Administradoras Locales (JAL) son no sólo el escenario de mayor participación de las mujeres en calidad de candidatas o aspirantes sino además la instancia donde han alcanzado el mayor porcentaje de éxito en la elección. Del total de 498 personas inscritas como candidatos/as a las JAL 354 (71\%) eran hombres y 144 (29\%) eran mujeres. Se eligieron 140 ediles distribuidos así: 36 mujeres que representan el 26\% y 104 hombres que corresponden al $74 \%$ para las 17 comunas y 3 corregimientos que componen el Municipio.

Figura 13. Número de elegidos por sexo en JAL

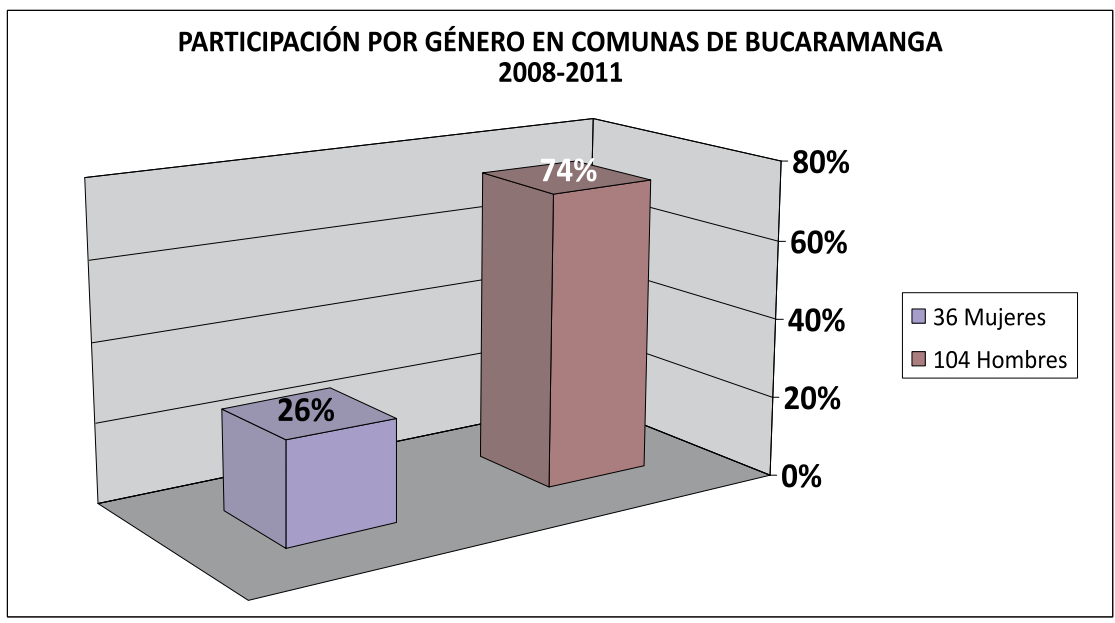

Fuente: Registraduría del Estado Civil. Gráfico elaborado por FMF.

\section{EN SÍNTESIS}

La participación es considerada vital para la construcción de una sociedad y un proyecto de ciudad, pero además, puede ser un camino para buscar concretar una igualdad de oportunidades que permita avanzar en la equidad entre los géneros, al incorporar la voz, las propuestas y acciones de las mujeres en su heterogeneidad y la de grupos sociales hasta ahora excluidos, para que sean recibidas y valoradas adecuadamente. 
A pesar de los avances registrados a nivel nacional, departamental y local todavía los avances democráticos siguen en deuda en términos de inclusión de las mujeres en los escenarios de decisión y cargos de elección popular, si tenemos en cuenta que las cifras de participación son todavía muy bajas en relación a la de los hombres.

Las mujeres no son un sector, son más de la mitad de la población. Las mujeres entonces están sub-representadas en la política, pero no es sólo una cuestión numérica; es un asunto de principios democráticos y de sesgos culturales sexistas y discriminatorios que requiere con urgencia ser abordados desde diferentes tópicos de intervención (investigación, medidas afirmativas en política y acción gubernativa, entre otros).

Las mujeres aunque han ganado autonomía, visión e identidad en el espacio público, en la práctica están incluidas muy deficientemente.

Los hechos demuestran una significativa participación y labor de las mujeres como líderes, pero lo que no se ha producido es el salto a la dirigencia.

\section{CONCLUSIONES}

La participación es considerada vital para la construcción de una sociedad y un proyecto de ciudad, pero además puede ser un camino para buscar concretar la igualdad de oportunidades que permita avanzar en la equidad entre los géneros, al incorporar la voz, las propuestas y acciones de las mujeres en su heterogeneidad y la de grupos sociales hasta ahora excluidos, para que sean recibidas y valoradas adecuadamente.

En Colombia la participación efectiva de las mujeres en las distintas regiones atraviesa por una serie de limitaciones enmarcadas en relaciones de poder desiguales entre mujeres y hombres. Esto evidencia una separación en el ordenamiento social, entre lo público y lo privado, que se ve reflejada en problemas de carácter estructural. Por ejemplo, la escasa participación política de las mujeres y las altas tasas de violencia intrafamiliar, impiden el ejercicio libre y autónomo de los derechos de las mujeres, reproducen esquemas de subordinación y perpetúan su discriminación en la sociedad.

En el Departamento de Santander de las 15 mujeres candidatas a la Cámara de Representantes en las elecciones de 2006 ninguna fue elegida; así como tampoco alcanzaron la curul las aspirantes mujeres al Senado. El porcentaje de participación femenina más alto ha sido en la Asamblea Departamental (período 2001-2003) cuando el $15,8 \%$ del total de diputados elegidos fueron mujeres. No obstante esta participación se reduce para el siguiente período y se mantiene con 2 curules en el período iniciado de acuerdo con los resultados electorales de octubre de 2007. 
La participación femenina en alcaldías y concejos se ha incrementado. En periodo 2004-2007 un total de 80 curules que equivalen al 9,1\% del total, tiene representación femenina y en las elecciones del período 2004-2007 se postularon 544 mujeres, sólo un $14,5 \%$ de los candidatos. Aunque es evidente la baja participación e inclusión de las mujeres frente a la de los hombres aún así, hay que señalar como hecho positivo la tendencia general de crecimiento en el porcentaje de participación en estas instancias de decisión.

En Bucaramanga, se inscribieron como aspirantes al concejo 288 candidatos/as distribuidos así: 254 hombres (88\%) y 34 mujeres (12\%), sin embargo, resultaron elegidos 14 hombres (74\%) y 5 mujeres (26\%), lo cual significa no sólo un incremento importante en la cuota de participación femenina pasando de 3 a 5 concejalas elegidas para el período 2008-2011, sino además un porcentaje de éxito de las mujeres equivalente al 15\%. Uno de los órganos de mayor participación femenina a nivel político en Bucaramanga se da en las comunas. Las Juntas Administradoras Locales (JAL) son no sólo el escenario de mayor participación de las mujeres en calidad de candidatas o aspirantes, sino además, la instancia donde han alcanzado el mayor porcentaje de éxito en la elección. Del total de 498 personas inscritas como candidatos/as a las JAL 354 (71\%) eran hombres y 144 (29\%) eran mujeres. Se eligieron 140 ediles distribuidos así: 36 mujeres que representan el 26\% y 104 hombres que corresponden al $74 \%$ para las 17 comunas y 3 corregimientos que componen el Municipio.

En síntesis, aún cuando la participación política de las mujeres se incrementa, la democracia colombiana sigue en deuda con ellas en términos de inclusión en los escenarios de decisión y cargos de elección popular, si se tiene en cuenta que las cifras de participación son todavía muy bajas en relación a la de los hombres. Las mujeres aunque han ganado autonomía, visión e identidad en el espacio público, en la práctica están incluidas muy deficientemente. Los hechos demuestran una significativa participación y labor de las mujeres como líderes, pero lo que no se ha producido es el salto a la dirigencia. Las mujeres no son un sector, son más de la mitad de la población. Las mujeres, entonces, están sub-representadas en la política, pero no es sólo una cuestión numérica; es un asunto de principios democráticos y de sesgos culturales sexistas y discriminatorios que requiere con urgencia ser abordados desde diferentes tópicos de intervención, investigación, medidas afirmativas en política y acción gubernativa.

\section{REFERENCIAS}

Arango, L; Guacaneme, F. (2005). Participación política de la Mujer en Colombia, Estudio apoyado por Fescol, Fenacon, GTZ, Federación Colombiana de Municipios y USAID, Bogotá, Colombia. 
Departamento Administrativo Nacional De Estadística. DANE, Censo General 2005.

. Proyecciones de Población 2005 - 2010.

. Población desagregada por sexo, Boletín, marzo de 2007.

trimestre $200 \overline{6}$. . Mercado laboral por sexo. Gran encuesta integrada de hogares IV

Declaración de Beijing, 1995.

Lamus, D. (2007). De la subversión a la inclusión: movimiento(s) de mujeres de la segunda ola en Colombia 1975-2005, tesis doctoral (inédita), Universidad Andina Simón Bolívar, Quito, julio de 2007.

Naciones Unidas-ONU. (1993). Conferencia mundial de derechos humanos, Declaración y Programa de Acción. Viena, 14 a 25 de Junio.

Observatorio de Asuntos de Género. Informe de gestión 2002-2005. Consejería Presidencial para la Equidad de la Mujer, Bogotá, 2006.

PROFAMILIA (200). El protocolo facultativo de la Convención de la Mujer, Bogotá, Espacio Libre, N. 6, noviembre de 2003.

Wills, M. (2005). Responsabilidad democrática de las mujeres, un mundo en construcción. Bogotá - Colombia.

. (2007). Inclusión sin representación, la irrupción política de las mujeres en Colombia 1970 - 2000. Editorial Norma, Bogotá.

\section{Legislación}

Ley 581 de 2000: Por la cual se reglamenta la adecuada y efectiva participación de la mujer en los niveles decisorios de las diferentes ramas y órganos del poder público, de conformidad con los artículos 13, 40, 43 de la Constitución Nacional.

Acto Legislativo No. 3 de 1954: Reformatorio de la Constitución Nacional por el cual se otorga a la mujer el derecho activo y pasivo del sufragio.

Ley 74 de 1968: Declaración Universal de los Derechos Humanos y Pacto Internacional de Derechos Económicos, Sociales y Culturales

\section{Sitios Web}

www.federacionnacionaldedepartamentos.org.co

www.un.org/spanish/abautun/charter.htm.

http://www.fao.org/Gender/static/Method/2statds1.htm 2008.

http://www.un.org/esa/gopher-data/conf/fwcw/off/a-20.sp, consulta febrero de

http://www.presidencia.gov.co/equidad/observatorio_genero.htm 
Tablas y figuras: estadísticas de género en la participación política.

Tabla 1. Comportamiento de la participación por género en Gobernaciones.

Tabla 2. Participación política por género en Santander.

Figura 1. Participación por género en el Congreso.

Figura 2. Participación por género en Asambleas Departamentales

Figura 3. Participación por género en Alcaldías.

Figura 4. Participación por género en Ministerios.

Figura 5. Participación por género Gobernaciones y Alcaldías.

Figura 6. Participación por género Congreso.

Figura 7. Participación por género en Rama Judicial.

Figura 8. Inscritos por partido y sexo a la Asamblea de Santander.

Figura 9. Número de diputados elegidos por sexo y partido.

Figura 10. Relación porcentual de potencial y votantes por sexo.

Figura 11. Inscritos por partido y sexo al Concejo de Bucaramanga.

Figura 12. Número de elegidos por sexo y partido al Concejo de Bucaramanga.

Figura 13. Número de elegidos por sexo en JAL. 